\title{
Complex Formation with Plasmid DNA Increases the Cytotoxicity of Cationic Liposomes
}

\author{
Lap Thi NGuyen,${ }^{a, b}$ Kazutaka Atobe, ${ }^{a}$ Jose Mario Barichello, ${ }^{a, c}$ Tatsuhiro IshidA, ${ }^{a}$ and \\ Hiroshi KIWADA *,a \\ ${ }^{a}$ Department of Pharmacokinetics and Biopharmaceutics, Subdivision of Biopharmaceutical Sciences, Institute of Health \\ Biosciences, The University of Tokushima; 1-78-1 Sho-machi, Tokushima 770-8505, Japan: ${ }^{b}$ Vietnam National Institute \\ of Drug Quality Control; 48-Hai Ba Trung Street, Hanoi, Vietnam: and ${ }^{c}$ Japan Association for the Advancement of \\ Medical Equipment; Tokyo 113-0033, Japan. Received November 27, 2006; accepted January 11, 2007
}

Cationic liposomes (CL) are one of the most widely studied non-viral vectors for gene delivery. It is wellknown that CL induces cytotoxicity following lipofection. However, little is known regarding the mechanism involved in the cytotoxicity. In this study, the in vitro cytotoxicity of CL and its complex with pDNA (lipoplex) was investigated, and a part of the mechanism of induction as well. While free pDNA did not show any cytotoxicity, pDNA increased the cytotoxicity of CL via the formation of lipoplex. In addition, the lipoplex-induced cytotoxicity increased in a lipoplex dose-dependent manner, irrespective of the type of pDNA, cell line and the absence or presence of serum. An assay showed that apoptosis was largely induced by treatment with the lipoplex (lipofection), but not with CL alone, in the tested range of concentration of CL and pDNA. Furthermore, following treatment with lipoplexes, the cells exhibited the morphological features of apoptosis and DNA fragmentation. A cDNA microarray study showed that the lipofection up-regulated 45 genes related to apoptosis, transcription regulation and immune response. These results clearly indicate that pDNA in the lipoplex increases the cytotoxicity of $\mathrm{CL}$ as a result of inducing apoptosis. The fundamental principle for gene therapy is to deliver gene-based therapeutics to target cells for specific gene targeting with minimal cytotoxicity. Our results suggest the possibility that cytotoxicity induced by lipofection, accompanied by gene changes, could intrinsically exacerbate, attenuate or even mask the desired effects of gene-based therapy.

Key words cationic liposomes; lipofection; cytotoxicity; plasmid DNA; transfection

Gene therapy has emerged as one of the most potent and promising strategies for the development of a treatment for inherited and acquired disorders with underlying genetic defects or malfunctions. ${ }^{1,2}$ Gene-based therapies require acceptable and efficient delivery along with minimal toxicity. Hence, viral and non-viral vectors have been extensively studied for in vivo and ex vivo gene transfer with the goal of developing a strategy that could lead to a large number of cells showing higher gene expression and minimum cytotoxic effects.

Nonviral vectors such as cationic liposomes (CL) have been shown to be generally preferred over viral-vectors because they are thought to be non-immunogenic, relatively easy to assemble, and amenable to scale-up for industrial production. ${ }^{3,4}$ Unlike viruses, they have no restrictions on the size of DNA to be delivered; CL can deliver nucleic acids of essentially unlimited size ranging up to large mammalian artificial chromosomes. CL can also be covalently grafted to receptor-specific ligands for targeted gene delivery. Therefore, since their first introduction as a potential delivery system in 1987, ${ }^{5)}$ DNA-cationic lipid complexes (lipoplexes) have been used in numerous research protocols for the delivery of genes, antisense oligonucleotides and siRNA in a range of cell types. Several lipoplex formulations have been evaluated in clinical treatment of cancer, ${ }^{6,7)}$ and cystic fibrosis. $^{8-10)}$

One of the prerequisites for the success of gene therapy is a safe and efficient gene delivery system. Thus, the risk associated with the exposure and the molecular mechanism of any cytotoxicity need to be well understood. But the related information is scant. Some in vitro studies have been shown that CL induces cytotoxic effects or apoptosis in several cell types, for example, in phagocytic macrophages or immune cells. ${ }^{11,12)}$ In addition, other studies have demonstrated that some cationic lipid-based transfection agents induced geneexpression changes in human epithelial cells. ${ }^{13)}$ However, these investigations are limited owing to the fact that they were concerned only with material-related intrinsic cytotoxicity.

Concerning lipoplex-induced toxicity, lipoplexes cause changes to cells, including cell shrinking, reduced number of mitoses, and vacuolization of the cytoplasma. ${ }^{14)}$ This toxicity may, in part, result from the large size or high positive zeta potential of the lipoplexes required for their uptake. ${ }^{15)}$ However, the detailed molecular mechanisms leading to cell death caused by lipoplexes are still not fully understood, thus it is important for us to decipher the origin and nature of the cytotoxicity and related molecular mechanisms.

In this study, we investigated the in vitro cytotoxicity of one of the most widely used CL, Lipofectamine 2000, and its complex with pDNA as well as a part of the mechanism of its induction. Furthermore, we examined the relationship between gene expression profile changes and the induced cytotoxicity. Our investigation may help to develop a novel CL mediated-gene delivery lipoplex formulation with a very low cytotoxicity.

\section{MATERIALS AND METHODS}

Materials Lipofectamine 2000 (LF2000) was purchased from Invitrogen (CA, U.S.A.). The luciferase assay kit and the cell culture lysis reagent (CCLR) were purchased from Promega (WI, U.S.A.). APOPercentage ${ }^{\mathrm{TM}}$ apoptosis assay kit was obtained from Biocolor (Northern Ireland, U.K.). Syto 
24 Green Fluorescence nucleic acid stain was purchased from Molecular Probes (Oregon, U.S.A.). Opti-MEM I medium was purchased from Life Technologies (MD, U.S.A.). The other cell culture reagents were obtained from Nissui Pharmaceutical (Tokyo, Japan). Other reagents were of analytical grade.

Cells HeLa cells (human cervix) were obtained from Dr. Yasuo Shinohara (Division of Gene Expression, Institute of Genome Research, the University of Tokushima, Japan). B16BL6 cells (mouse murine melanoma) were generous gift from Dr. Naoto Oku (Department of Medical Biochemistry, University of Shizuoka, Japan). RGC-6 cells (rat brain, glioma) were obtained from Cell Resource Center for Biomedical Research (Tohoku University, Japan).

Plasmid The pDNAs, pGL3-Control containing the cDNA of firefly luciferase (Promega, WI, U.S.A.), pORF9mPTEN containing the cDNA of mPTEN (InvivoGen, CA, U.S.A.) and pEGFP-N1 containing the cDNA of EGFP (BD Biosciences, CA, U.S.A.) were propagated in Escherichia coli and isolated using a plasmid Giga kit (Qiagen, Hilden, Germany). The DNA concentration was determined by measuring the UV absorbance at $260 \mathrm{~nm}$. Purity was confirmed by agarose gel electrophoresis. Another pDNA, pCpG-mcs G2 containing an MCS (Multiple Cloning Site) with several commonly used restriction sites, for convenient cloning of a CpG-free gene, was purchased from InvitroGen and kindly propagated by Dr. Naoshi Yamazaki (Department of Medicinal Biochemistry, Institute of Health Biosciences, the University of Tokushima, Japan).

Preparation of Lipoplexes Lipoplexes of CL with pDNA were prepared as recommended by the manufacturer. Briefly, LF2000 in Opti-MEM I medium was added to vials containing pDNA in Opti-MEM I. They were vortexed at low speed for $20 \mathrm{~s}$ to avoid pDNA shearing and the lipoplexes were allowed to form for $20 \mathrm{~min}$ at room temperature. Four lipoplex formulations were prepared by keeping constant the pDNA amount $(0.2 \mu \mathrm{g} /$ well $)$ while the LF2000 amount was varied $(0.25,0.5,1$, and $2 \mu \mathrm{l} /$ well $)$. Four other formulations were prepared by keeping the optimal charge ratio recommended by the manufacturer constant (pDNA $(\mu \mathrm{g}):$ LF2000 $(\mu \mathrm{l})$ ratio at $1: 2.5)$ and proportionally increasing the amount of both pDNA and LF2000.

Lipofection Cells were seeded in 96 well-plates at a density of $1 \times 10^{4}$ cells/well $24 \mathrm{~h}$ prior to the lipofection in growth medium (DMEM) supplemented with 10\% heat-inactivated fetal bovine serum (FBS), $10 \mathrm{~mm}$ glutamine, and $100 \mathrm{U} / \mathrm{ml}$ penicilline and $100 \mu \mathrm{g} / \mathrm{ml}$ streptomycine. Cultures were maintained at $37^{\circ} \mathrm{C}$ in a $5 \% \mathrm{CO}_{2}$ air incubator. Different amounts of LF2000 alone or lipoplexes were added to the wells and the final volume was set to $100 \mu \mathrm{l} /$ well with serum free Opti-MEM I or with Opti-MEM I containing 10\% FBS. After $4 \mathrm{~h}$ of lipofection, the medium was replaced with fresh growth medium after washing twice with cold phosphate buffered saline (PBS).

Evaluation of Cytotoxicity An MTT assay was employed to determine the cytotoxicity of cells as a result of $4 \mathrm{~h}$ exposure to naked pDNA, LF2000 alone and lipoplexes. The growth medium was removed $24 \mathrm{~h}$-post lipofection and the cells were washed with PBS. Fifty microliters of 3-(4,5-dimethylthiazol-2-yl)-2,5-diphenyl tetrazolium bromide $(0.5$ $\mathrm{mg} / \mathrm{ml}$ ) was added to each well and further incubated for $4 \mathrm{~h}$.
The formazan was dissolved in $150 \mu$ l of 2-propanol $/ \mathrm{HCl}$ and incubated for $30 \mathrm{~min}$ at $37^{\circ} \mathrm{C}$. The absorbance of each well was read at $570 \mathrm{~nm}$ on a microplate reader Wallac 1420 ARVOsx (PerkinElmer, Trukn, Finland). Cytotoxicity data were expressed as the percentage absorbance relative to untreated control cells.

\section{Apoptosis Assay}

Assessment of Morphological Changes To assess the morphological changes, untreated cells, LF2000-treated cells ( $2 \mu \mathrm{l} /$ well $)$ and lipofected-cells $(0.8 \mu \mathrm{g}$ pGL-3-Control $/ 2 \mu \mathrm{l}$ $\mathrm{CL} /$ well), were washed once with PBS at $8 \mathrm{~h}$ post-lipofection and the cells were then stained with Syto 24 Green Fluorescence Nucleic acid stain. Apoptotic cells were detected by fluorescence confocal microscopy (Carl Zeiss, Oberkochen, Germany).

DNA Fragmentation Assay At 24 h post-lipofection, untreated cells, naked pDNA-treated cells $(0.8 \mu \mathrm{g} /$ well $)$, LF2000-treated cells $(2 \mu \mathrm{l} /$ well $)$ and lipofected cells $(0.8 \mu \mathrm{g}$ pGL-3-Control $/ 2 \mu \mathrm{l} \mathrm{CL} /$ well) were washed once with PBS. Approximately $5 \times 10^{7}$ cells were then harvested by trypsinization and lysed by mixing with a $100 \mu \mathrm{l}$ of lysis buffer (10 mm Tris-HCl (pH 7.5), 10 mm EDTA (pH 8), 1\% Triton $\mathrm{X}-100)$ at $4{ }^{\circ} \mathrm{C}$ for $10 \mathrm{~min}$. The lysate was centrifuged at $16000 \mathrm{rpm}$ for $5 \mathrm{~min}$ to separate the fragment DNA (supernatant) from intact chromatin (pellet). The solution containing low molecular mass DNA was treated with $200 \mu \mathrm{g}$ RNase A for $10 \mathrm{~min}$ at $37^{\circ} \mathrm{C}$ to digest RNA and with $200 \mu \mathrm{g}$ proteinase $\mathrm{K}$ for $1 \mathrm{~h}$ at $50{ }^{\circ} \mathrm{C}$ to digest protein. DNA was precipitated with $20 \mu \mathrm{l} 5 \mathrm{M} \mathrm{NaCl}$ and $120 \mu \mathrm{l}$ isopropanol for $2 \mathrm{~h}$ at $-20^{\circ} \mathrm{C}$, and then centrifuged at $16000 \mathrm{rpm}$ for $15 \mathrm{~min}$ and washed once with $0.5 \mathrm{ml}$ ice cold $70 \%$ ethanol. The pellets were dissolved in $30 \mu \mathrm{l}$ TE buffer $(10 \mathrm{~mm}$ Tris- $\mathrm{HCl}, 1 \mathrm{~mm}$ EDTA (pH 8)) and subjected to $2 \%$ agarose gel electrophoresis at $50 \mathrm{~V}$ in TAE buffer for about $1.5 \mathrm{~h}$. DNA was visualized by ethidium bromide staining under UV light (ATTO, Tokyo, Japan).

Quantitative Measurement of Apoptosis The APOPercentage $^{\mathrm{TM}}$ apoptosis assay kit was used to quantify apoptosis according to the manufacturer's instructions. The APOPercentage dye was added to the cells at $8 \mathrm{~h}$ post-lipofection and incubated for $1 \mathrm{~h}$ at $37^{\circ} \mathrm{C}$. The cells were washed twice with PBS, and immediately examined under fluorescent microscopy. The percentage apoptosis was determined by counting the cells under light microscopy. At least 200 cells were counted from randomly selected fields in two independent observation sessions.

Microarray Analysis Total RNA was extracted from cells that had been treated with naked pDNA, LF2000 alone, or lipoplexes by means of RNeasy micro kit (Qiagen). The RNAs were amplified, converted to complementary DNAs and labeled with Cy-5-CTP using the Low RNA Fluorescent Linear Amplification kit (Agilent Technologies, CA, U.S.A.). As a result, the amplified complimentary RNA products were labeled with Cy-5. As a control, Cy-3 labeled reference human RNA was used. Labeled cRNAs were then fragmented and hybridized using Agilent's in situ hybridization plus kit on Human1A ver.2 Oligo Microarray (Agilent Technologies). The arrays were scanned using an Agilent Technologies Microarray Scanner (Agilent Technologies). The microarray consisted of 20227 genes including genes related to cell cycle regulation, apoptosis-related, DNA transcription 
factors/damage response/repair and recombination, metabolism, translation/cytokines. The experiment was performed according to the manufacturer's protocol. The data were analyzed with the GeneSpring software (Agilent Technologies).

In this study, data from each gene were typically reported as a base 2 logarithm of the expression ratio of the control. One way analysis of variance (ANOVA) followed by multiple comparison test (post-hoc) and/or unpaired two-tailed $t$-test were used with an assumption of $p$ value less than 0.05 for significant differences.

\section{RESULTS}

Lipoplexes Induced Marked Cytotoxicity Compare to CL Alone The effect of treatment with CL alone on cytotoxicity was compared to the effect of treatment with their lipoplex in HeLa cells (Fig. 1). Cells were treated with various amounts of CL alone or with different lipoplexes prepared by varied CL amount $(0.25,0.5,1,2 \mu \mathrm{l} /$ well) with constant pDNA amount $(0.2 \mu \mathrm{g} / \mathrm{well})$. CL alone induced only a slight cellular toxicity in the range of CL tested, irrespective of the absence (Fig. 1 left) or presence (Fig. 1 right) of serum. While, in the similar experimental conditions, lipoplexes induced a significant cytotoxicity compared to CL alone and the cytotoxicity increased as the CL content in the lipoplex increased $(p<0.01)$.

The effect of the amount of lipoplex on cytotoxicity was examined using lipoplexes in which the pDNA $(\mu \mathrm{g}): \mathrm{CL}(\mu \mathrm{l})$ ratio was kept at $1: 2.5$ (Fig. 2). The induced cytotoxicity increased in a lipoplex dose-dependent manner, irrespective of the absence (Fig. 2 left) or presence (Fig. 2 right) of serum. The cytotoxicity in the lipoplex-treated cells was markedly higher than either CL- or pDNA-treated cells. Through this experiment, pDNA itself did not show any cytotoxicity in the range of concentrations used, while $\mathrm{CL}$ alone showed a slight cytotoxicity. A similar tendency in terms of cytotoxicity was observed for the other two cell lines (RGC-6 and B16BL6) (data not shown).

In order to determine whether different pDNAs lead to different levels of cytotoxicity, lipoplexes were prepared with $\mathrm{CL}$ and three different pDNAs (pGL3-Control, pORF9mPTEN or pEGFP-N1). All lipoplexes induced a similar level of cytotoxicity (data not shown). In addition, to circumvent the possibility that $\mathrm{CpG}$ motifs in the pDNA sequence
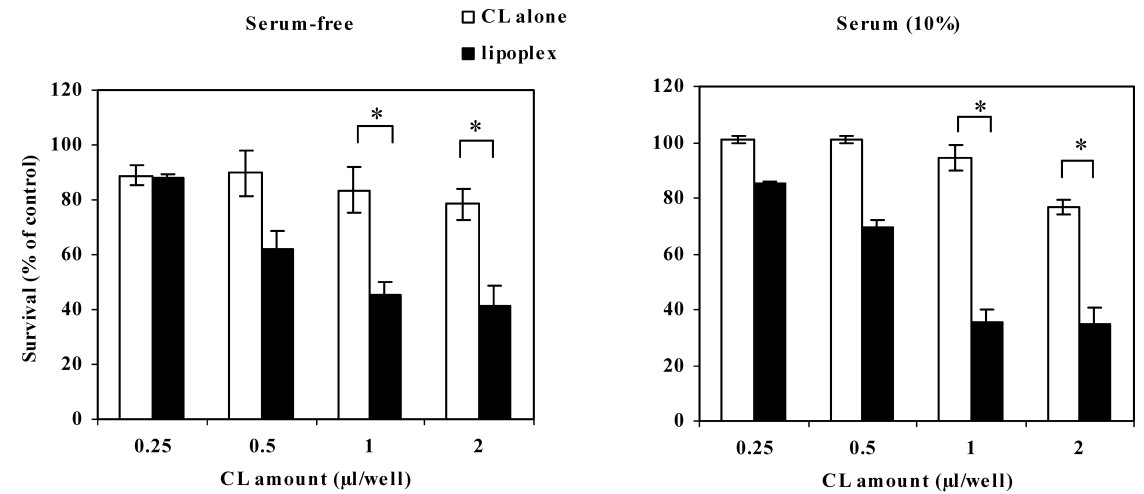

pDNA amount was fixed at $2 \mu \mathrm{g} / \mathrm{well}$

Fig. 1. Cytotoxicity Induced by CL Alone or Lipoplex

Cells were treated with CL alone (open column) or lipoplex (pGL-3-Control/CL) (closed column) in the absence of serum (left) or presence of $10 \%$ FBS (right) for $4 \mathrm{~h}$. Twenty four hours post-lipofection, cytotoxicity was determined by an MTT assay according to the methods described in Materials and Methods. Data are the mean \pm S.D. $(n=3)$ from three independent experiments. Significant statistical difference of cytotoxicity between lipoplexes and CL alone are reported as $* p<0.01$.
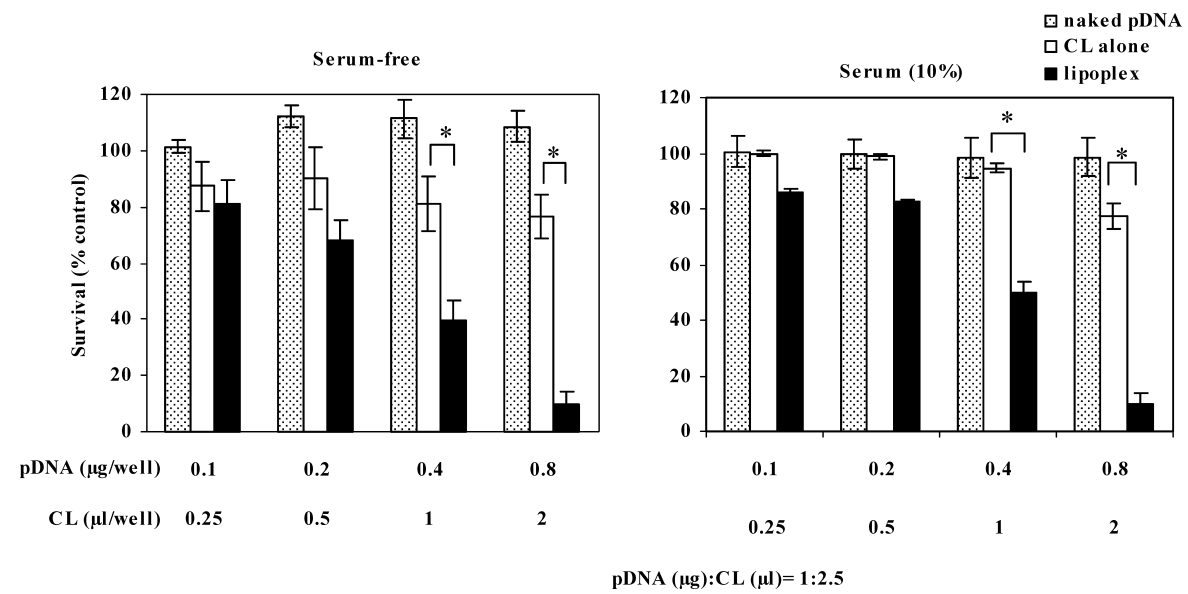

Fig. 2. Effect of Lipoplex-Dose on the Induced Cytotoxicity

Cells were treated with naked pDNA (pGL-3-Control) (dotted column), CL alone (open column) or lipoplex (closed column) in the absence of serum (left) or presence of $10 \%$ FBS (right) for $4 \mathrm{~h}$. At $24 \mathrm{~h}$ post-lipofection, cytotoxicity was determined by an MTT assay according to the methods described in Materials and Methods. Data are mean \pm S.D. $(n=3)$ from three independent experiments. Significant statistical difference of cytotoxicity between lipoplexes and CL alone are reported as $* p<0.01$. 
may lead to cell death associated with the inflammatory toxicity, further investigations were carried out (Fig. 3). The cytotoxicity induced by lipoplexes including $\mathrm{CpG}$-free pDNA was similar to that induced by lipoplexes including $\mathrm{CpG}$ motif-containing pDNA.

Apoptosis Induced in Lipofected Cells To investigate if the cell death induced by lipoplex or CL alone was caused via apoptosis, apoptosis was evaluated with two different methods: agarose gel electrophoresis to determine DNA fragmentation (the hallmark of apoptosis) and cellular morphological analysis. Treatment with lipoplex induced substantial DNA fragmentation, while treatment with CL alone induced only minimal DNA fragmentation and treatment with pDNA failed to induce any DNA fragmentation (Fig. 4A). A fluorescence microscopic image of non-treated cells and CL-treated cells showed a normal nuclear morphology with a large nuclei and evenly distributed chromatin (Fig. 4B and Fig. 4C, respectively). In contrast, nuclei with condensation chromatin were clearly observed in the cells that had been treated with lipoplex (Fig. 4D).

In addition, the induced apoptosis was quantitatively assessed using the APOPercentage apoptosis assay. This assay reflects the translocation of plasma membrane phosphatidylserine that is produced in the early apoptosis process. Following treatment with various amounts of $\mathrm{CL}$ alone and

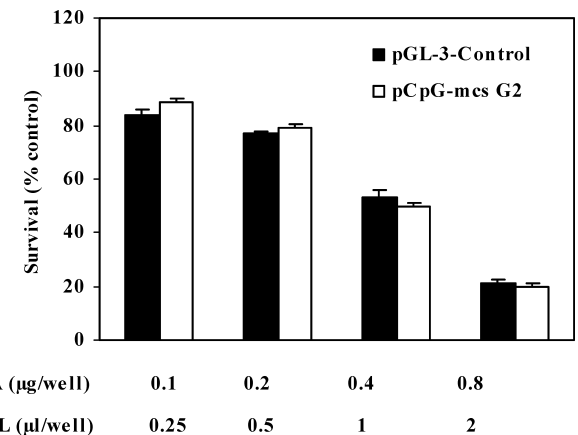

Fig. 3. Effect of Different pDNAs in the Lipoplex on the Induced Cytotoxicity

Cells were treated with lipoplex containing pGL-3-Control (closed column) or lipoplex containing pCpG-mcs G2 (opened column) for $4 \mathrm{~h}$. After $24 \mathrm{~h}$ lipofection, cytotoxicity was determined using an MTT assay according to the methods described in Materials and Methods. Data are mean \pm S.D. $(n=3)$ from three independent experiments.

(A)

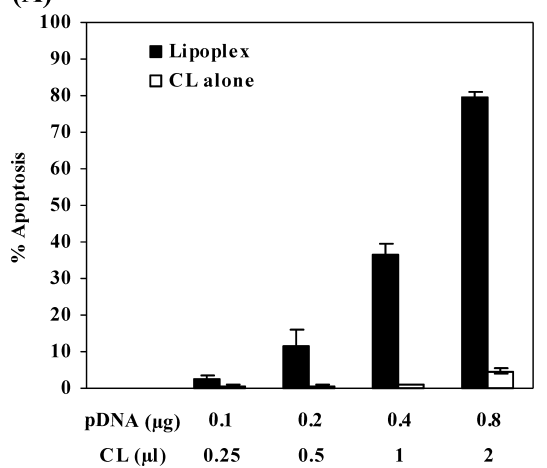

lipoplex, the assay was carried out at $8 \mathrm{~h}$ post-lipofection. Apoptosis was caused by treatment with lipoplex in a lipoplex-dose dependent manner (Fig. 5A). More than $80 \%$ of the cells were apoptotic at the highest lipoplex dose (CL and pDNA amounts were $2 \mu \mathrm{l} /$ well and $0.8 \mu \mathrm{g} /$ well, respectively) used in the treatment. In addition, the effect of the pDNA content in lipoplex in causing apoptosis was investigated as the level of CL was kept at $2 \mu \mathrm{l} /$ well (Fig. 5B). The apoptosis percentage increased as the pDNA content was reinforced in the lipoplex formulations. Naked pDNA $(0.8$ $\mu \mathrm{g} /$ well) did not lead to any apoptosis,

Up or Down-Regulated Genes as a Result of Treatment with Lipoplex or CL Alone In order to understand what occurred in cells following lipofection, gene expression pro-
(A)
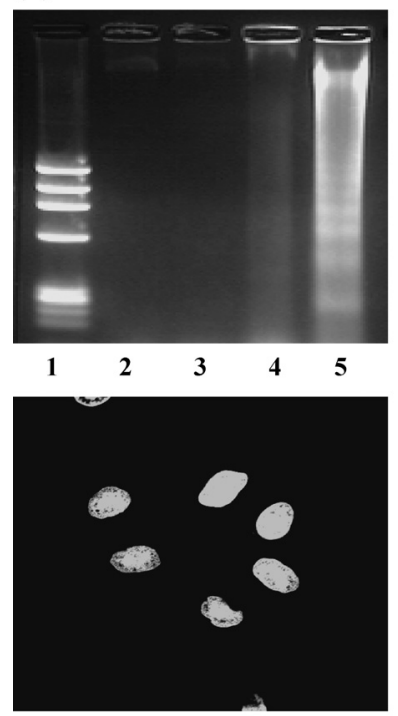

(C)
(B)
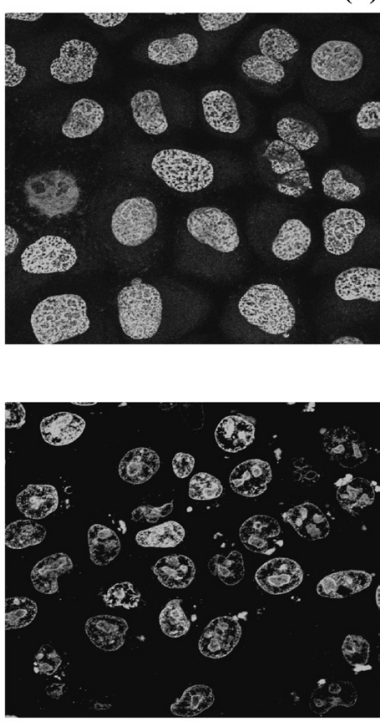

(D)
Fig. 4. DNA Fragmentation and Morphological Analysis

(A) Agarose gel electrophoresis of DNA extracted from HeLa cells at $12 \mathrm{~h}$ after treatment with naked pDNA, CL alone or lipoplex was carried out as described in Materials and Methods. Lane 1: DNA marker ( $\Phi$ X174 DNA-Hae III Digest (New England BioLabs, MA, U.S.A.), $1 \mu \mathrm{g} /$ well). Lane 2: Non-treated cells. Lane 3: Naked pDNA (pGL-3-Control), Lane 4: CL alone $(2 \mu \mathrm{l} /$ well). Lane 5: Lipoplex $(0.8 \mu \mathrm{g}$ pGL-3-Control/2 $\mu \mathrm{l} \mathrm{CL} /$ well). (B-D) Morphological analysis in HeLa cells after $8 \mathrm{~h}$ treatment was done: (B): non-treated cells, (C): $\mathrm{CL}$ alone $(2 \mu \mathrm{l} /$ well), (D): lipoplexes $(0.8 \mu \mathrm{g}$ pGL-3-Control $/ 2 \mu \mathrm{l} \mathrm{CL} /$ well). A similar result was observed in three independent experiments and a typical result was shown.

(B)

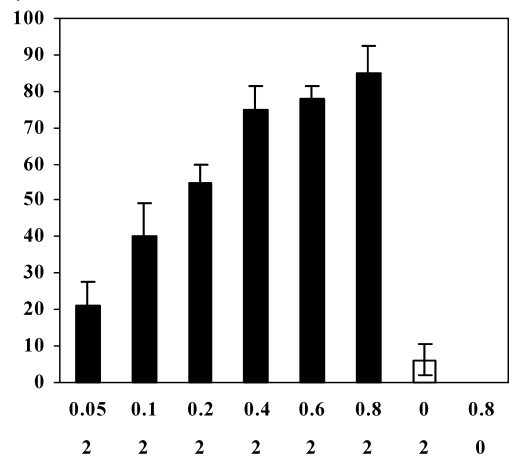

Fig. 5. Effect of Lipoplex-Dose (A) or Amount of pDNA in the Lipoplex (B) on the Lipoplex-Induced Apoptosis

(A) Percent apoptosis of HeLa cells after a $4 \mathrm{~h}$ treatment with various amounts of CL (opened column) and their lipoplexes (pGL-3-Control/CL) (closed column) were determined as described in the Materials and Methods. (B) Apoptosis percentages of HeLa cells after $4 \mathrm{~h}$ treatment with lipoplexes containing different amount of pDNA (pGL-3-Control) but a constant amount of CL was determined. Values are expressed as mean \pm S.D. of at least 200 cells from randomly selected fields were counted by two independent observations. 
Table 1. Summary of Genes Changed by the Treatments

\begin{tabular}{|c|c|c|c|c|}
\hline GenBank & Gene category & Gene title & $\begin{array}{l}\text { CL alone } \\
\mathrm{FC}^{a)}\end{array}$ & $\begin{array}{l}\text { Lipoplex } \\
\mathrm{FC}^{a)}\end{array}$ \\
\hline NM_005347 & $\begin{array}{l}\text { ATP binding; protein binding, stress } \\
\text { response }\end{array}$ & HSPA5, heat shock protein $70 \mathrm{kDa}$ protein 5 & 1.305 & 4.05704 \\
\hline NM_017510 & Protein carrier & HSGP25L2G, gp25L2 protein & 1.1633 & 4.24495 \\
\hline NM_004419 & Cell cycle/protein modifier & DUSP5, dual specificity phosphatase 5 & 1.5863 & 4.65321 \\
\hline NM_002923 & Cell cycle & RGS2, regulator of G-protein signaling 2 & 1.9277 & 4.94052 \\
\hline NM_004417 & Cell cycle/protein modifier & DUSP1, dual specificity phosphatase 1 & 1.6989 & 6.69753 \\
\hline NM_014685 & Protein modifier & HERPUD1, endoplasmic reticulum tress response-inducible & 2.8895 & 15.4729 \\
\hline X89399 & GTPase activator activity & GAP1 IP4BP, RAS p21 protein activator 3 & 0.9516 & 21.1763 \\
\hline NM_002133 & Anti-apoptosis, growth factor & $\begin{array}{l}\text { HO-1, heme oxygenase (decyclizing) activity; } \\
\text { oxidoreductase activity; signal transducer activity }\end{array}$ & 4.7743 & 2.71169 \\
\hline NM_001657 & Anti-apoptosis, growth factor & AREG, amphiregulin preproprotein & 1.6699 & 4.97542 \\
\hline NM_003407 & DNA binding, pro-apoptosis & TTP, zinc finger protein 36 & 1.676 & 5.45199 \\
\hline NM_001300 & Pro-apoptosis & KLF6, suppression of tumorigenicity 12 & 2.0236 & 5.52261 \\
\hline NM_021127 & Apoptosis & NOXA, phorbol-12-myristate-13-acetate-induced protein 1 & 1.8397 & 6.34913 \\
\hline NM_004083 & Cell cycle arrest, pro-apoptosis & CHOP, DNA damage-inducible transcript 3 & 2.3735 & 7.08512 \\
\hline NM_004024 & Transcription factor/pro-apoptosis & ATF3, transcription factor activity & 2.0929 & 8.95974 \\
\hline NM_002228 & Transcription factor/pro-apoptosis & $\mathrm{AP} 1$, activator protein $1 ; \mathrm{JUN}$ & 2.7726 & 10.0429 \\
\hline NM_005252 & DNA binding, pro-apoptosis & FOS, v-fos FBJ murine osteosarcoma viral oncogen homolog & 2.9243 & 14.9736 \\
\hline NM_001964 & Transcription factor/pro-apoptosis & EGR1, early growth response 1 & 2.1906 & 17.4851 \\
\hline NM_021052 & Transcription factor/DNA binding protein & HIST1H2AE, H2A histone family, member A & 1.777 & 4.11556 \\
\hline NM_003530 & Transcription factor/DNA binding protein & HIST1H3D, H3 histone family, member B & 3.0309 & 5.09793 \\
\hline NM_021968 & Transcription factor/DNA binding protein & HIST1H4J, H4 Histone family, member E & 2.4303 & 5.29728 \\
\hline NM_004414 & Transcription factor/DNA binding protein & DSCR1, calcipressin 1 aciform a & 2.6586 & 5.54703 \\
\hline NM_003518 & Transcription factor/DNA binding protein & HIST1H2BG, H2B histone family, member A & 1.9303 & 5.58707 \\
\hline S62138 & Transcription factor/DNA binding protein & TLS/CHOP, fusion protein, TLS/CHOP & 1.6422 & 5.64676 \\
\hline NM_003537 & Transcription factor/DNA binding protein & HIST1H3B, H3 histone family, member L & 2.6696 & 6.85893 \\
\hline NM_003548 & Transcription factor/DNA binding protein & HIST2H4, histone 2, H4 & 5.9915 & 9.4456 \\
\hline NM_003509 & Transcription factor/DNA binding protein & HIST1H2AI, H2A histone family, member C & 4.1403 & 10.2784 \\
\hline NM_003543 & Transcription factor/DNA binding protein & HIST1H4H, H4 Histone family, member $\mathrm{H}$ & 6.8413 & 10.8678 \\
\hline NM_003540 & Transcription factor/DNA binding protein & HIST1H4F, H4 histone family, member C & 9.0812 & 13.2378 \\
\hline NM_003955 & Immune response & SSI-3, suppressor of cytokine signaling 3 & 1.6258 & 4.72137 \\
\hline NM_001511 & Immune response & CXCL1; GRO1, chemokine ligand 1 & 1.5064 & 4.871 \\
\hline NM_002089 & Immune response & CXCL2, chemokine ligand 2 & 1.4233 & 4.87239 \\
\hline NM_006417 & Immune response & $\begin{array}{l}\text { IFI44, interferon induced, hepatitis C-associated } \\
\text { microtubular aggregate }\end{array}$ & 1.0206 & 7.33255 \\
\hline NM_001549 & Immune response & $\begin{array}{l}\text { IFIT3, interferon induced protein with tetratricopeptide } \\
\text { repeats } 3\end{array}$ & 0.9638 & 7.34021 \\
\hline NM_002201 & Immune response, cell proliferation & ISG20, interferon stimulated gene $20 \mathrm{kDa}$ & 1.1346 & 7.4357 \\
\hline NM_000600 & Immune response, apoptosis & IL6, interferon, beta 2 & 1.1069 & 7.50226 \\
\hline NM_003733 & Immune response & p59OASL, 2'-5'-oligoadenylate synthetase-like & 0.752 & 11.1649 \\
\hline NM_005101 & Immune response, protein binding & IFI15, interferon, alpha-inducible protein $15 \mathrm{kDa}$ & 1.0911 & 13.934 \\
\hline NM_014314 & Immune response & $\begin{array}{l}\text { DDX58, DEAD/H(Asp-Glu-Ala-Asp/His) box polypeptide } \\
\text { RIG-I }\end{array}$ & 1.0536 & 17.2823 \\
\hline ВС009507 & Immune response, protein binding & IFI15, inteferon, alpha-inducible protein $15 \mathrm{kDa}$ & 1.1798 & 19.6599 \\
\hline NM_001548 & Immune response & IFIT1, inteferon, alpha-inducible protein 56 & 1.1199 & 20.9507 \\
\hline NM_001547 & Immune response & $\begin{array}{l}\text { IFIT2, interferon induced protein with tetratricopeptide } \\
\text { repeats } 2\end{array}$ & 1.6092 & 72.5171 \\
\hline A_23_P57836 & Unknown & Unknown & 1.9254 & 4.2029 \\
\hline AB040917 & Unknown & KIAA1484, KIAA1484 protein & 0.8935 & 4.92871 \\
\hline A_23_P21293 & Unknown & Unknown & 1.1315 & 6.00392 \\
\hline ВC018929 & & PHLDA1, PHLDA1 protein & 2.6866 & 12.1289 \\
\hline
\end{tabular}

45 genes up- or down-regulated by treatment with lipoplex or CL alone (Fig. 6) were identified are listed. Each gene is denoted by the GeneBank accession number and the Gene Ontology (http://www.geneontology.org/), the annotations for Biological process and Molecular function. a) FC: Fold changes in gene expression represented the ratio of the samples treated with either CL alone or lipoplex divided by those of untreated cells.

files were examined by a microarray analysis. The microarray study showed that 45 gene-expressions were significantly up- or down-regulated following treatment with $\mathrm{CL}$ alone and lipoplex (Fig. 6). The exact identity of 45 genes changed are listed in Table 1. Several structure-function categories were represented in the list of differently expressed genes, i.e., cell cycle, apoptosis-related, DNA-binding, transcription, and immune response. Among them, a great number of proapoptotic genes including TTP (zinc finger protein 36), KL6 (suppression of tumorrigenecity 12), NOXA (phorbol-12- myristate-13-acetate-induced protein 1), CHOP (DNA damage-inducible transcript 3), ATF3 (transcription factor activity), AP1 (activator protein 1), FOS (v-fos FBJ murine osteosarcoma viral oncogene homolog), and EGR1 (early growth response 1) were observed. This proves that lipoplex induced cell death via the apoptosis pathway. In addition, some genes related to the regulation of DNA binding, transcription factors and pro-inflammatory cytokines including interleukin (IL6) and interferon- $\alpha$, were up-regulated. 


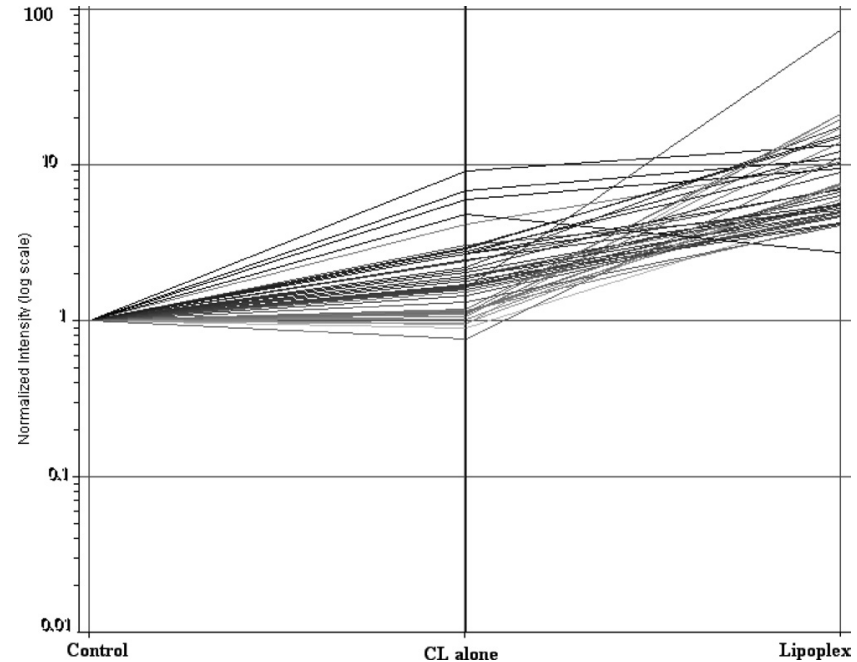

Fig. 6. Up or Down-Regulation of Genes by Treatment with Lipoplex or CL Alone

Comparative microarray was carried out following treatment with $\mathrm{CL}$ alone ( $2 \mu \mathrm{l} /$ well) or lipoplex $(0.8 \mu \mathrm{g}$ pGL-3-Control/2 $\mu \mathrm{l} \mathrm{CL} /$ well $)$.

\section{DISCUSSION}

A fundamental principle of gene therapy is to deliver gene-based therapeutics into target cells for specific gene targeting with minimal cytotoxicity. CL has been extensively investigated as a potentially safer alternative for gene delivery. However, the results described here indicated that the cytotoxicity of CL is further increased by the formation of a complex with non-toxic pDNA (lipoplex) and that this lipoplex results in cellular apoptosis. In addition, 45 genes were up-regulated as a result of lipofection. Such synergistic cytotoxicity induced by $\mathrm{CL}$ and pDNA, accompanied by gene-expression up-regulation, may intrinsically affect the outcome of gene therapy.

The remarkable cytotoxicity was caused as lipoplex was exposed to the cells, while no distinct cytotoxicity was found for the uncomplexed material (either CL or pDNA alone) (Figs. 1, 2). In addition, the cytotoxicity increased with increasing lipoplex dose (Figs. 2, 5A) or pDNA content in the lipoplex (Fig. 5B). These results clearly indicate that there is a synergism between CL and pDNA in causing cytotoxicity. It is likely that such induced cytotoxicity is not necessarily related to cell type or pDNA type. Some reports have demonstrated the pDNA carrying therapeutic genes is associated with the inflammatory toxicity of lipoplex. ${ }^{16,17)}$ This is thought to be due to the fact that the non-mammalian genes are recognized as foreign DNA due to the presence of a specific motif, $\mathrm{CpG}$ dinucleotids. ${ }^{18)}$ Our results strongly suggest that the induced cytotoxicity is not as a consequence of inflammation-like stimulation by $\mathrm{CpG}$ motif of pDNA in the lipoplex (Fig. 3).

The application of functional genomics technologiesmeaning the profiling of differential expression for many genes simultaneously by cDNA microarrays has proven to be very promising over recent years and was used to predict the toxic properties of one compound. ${ }^{19)}$ The potential benefit of using microarray analysis may provide insights into the mechanisms responsible for the lipoplex-induced cytotoxicity observed in this study. We demonstrated that 45 genes were significantly up-regulated in HeLa cells as a result of treatment with lipoplex, which are involved in a wide spectrum of biological processes and molecular functions, such as apoptosis, cell cycle control, DNA binding/transcription factors, and immune response. Lipoplex much strongly induced up-regulation of genes than that of CL alone (Fig. 6, Table 1). There seems to be a good correlation between cytotoxicity and up-regulation of gene-expression induced by lipoplex.

In cells exposed to lipoplex, pro-apoptosis related genes were significantly over-expressed, including NOXA, CHOP, ATF3, AP1, FOS, and EGR1 (Table 1). The identification of the function of these genes may be important in understanding the lipoplex-induced cytotoxic mechanism. It has been shown that the over-expression of NOXA induces apoptosis. $^{20,21)}$ NOXA was identified as a novel BH-3 only protein that is activated by endoplasmic reticulum (ER) stress at the transcript level. ${ }^{22}$ CHOP, Growth arrest- and DNA damageinducible gene 153 (GADD153), which belongs to a member of the CCAAT/enhancer-binding protein (C/EBP) family of transcriptional factors. The over-expression of $\mathrm{CHOP}$ results in cell growth arrest and apoptosis, its function is antagonized by BCL-2. ${ }^{23)} \mathrm{CHOP}$ is one of the components of the ER stress-mediated apoptosis pathway and much is known on the roles of this molecule on apoptosis. ${ }^{23-26)}$ AP-1 is known to modulate apoptosis. ${ }^{27)}$ Some reports have indicated that AP-1 plays an important role in the induction of $\mathrm{CHOP}$ gene expression. ${ }^{28-30)}$ FOS is also a major component of the AP-1 transcription factor complex. The expression of FOS may result from up-regulation of AP-1 and CHOP (Table 1). Activating transcription factor 3 (ATF3), a member of the ATP/CREB family, is rapidly induced by a wide range of stresses including genotoxic stresses and is involved in cell growth, apoptosis and invasion. ${ }^{31)}$ It has been reported that ATF3 is activated by $\mathrm{JNK}^{32)}$ and that JNK and ATF3 are activated through ER stress. ${ }^{33)}$ AFT3 can also function as a stress-inducible transcriptional repressor for CHOP gene. ${ }^{34)}$ The results of previous functional studies suggest that the early growth response 1 gene (EGR-1) is an anti-proliferative signal for tumor cells ${ }^{35,36)}$ and that the gene acts as to increase the potency of apoptotic agents. ${ }^{37,38)}$ Another report indicated that the overexpression of EGR-1 protein induced ATF3 expression, ${ }^{39)}$ which is consistent with our results showing that EGR1 expression was significantly increased, leading to an increased up-regulation of ATF3 (Table 1). It should be noted that most of the pro-apoptosis genes that are up-regulated by lipofection are related to the ER stress-mediated apoptosis pathway. The ER is the site for synthesis, folding, modification and trafficking of secretory and cell-surface proteins. It has been reported that ER stress could be elicited in the cell culture system by pharmacological agents, severe or prolonged ER stress can lead to cell death through apoptosis. $^{25)}$ Therefore, it appears that a stronger induction in ER stress due to lipofection leads to a greater apoptosis, although further experiments will be necessary to confirm the exact mechanism for causing apoptosis by lipofection.

From our results, the lipoplex appears to be an extremely potent inducer of the immune response (Table 1). Interferon $\alpha$ (IFI15 and IFI1) and interleukin 6 (IL6), up-regulated by lipofection in this study were reported to induce apoptosis. ${ }^{40)}$ It is also well-known that interferons cause an inhibition of 
cell proliferation. ${ }^{41-43)}$ Thus, it is possible that interactions with the lipoplex, but not pDNA or CL alone, modulates and triggers some gene expressions, which are involved in programmed cell death or cytokine generation of innate or adaptive immune reactions. Consequently, cells treated with lipoplex die via apoptosis.

To our knowledge, the results presented here show, for the first time, that lipoplex induces a much stronger cytotoxicity than CL, consequently leading to cell death via the apoptosis pathway in non-phagocytic or immune cells. Our results clearly indicate that CL and pDNA have a synergism in causing cytotoxicity, although both are non-toxic when used in treating cells. Such synergistic cytotoxicity, accompanied by gene-expression changes, may intrinsically affect the outcome of gene therapy. Further investigations of other types of CL and targeted cells both in vitro and in vivo will be necessary to elucidate the comprehensive toxicogenomic impact of CL-based formulations for gene therapy.

Acknowledgments The authors wish to thank Kinuka Yamane (Hokkaido System Science) for her technical assistance and helpful discussion and Dr. Milton S. Feather for his helpful comments in writing the English manuscript. This study was supported, in part, by Health and Labour Sciences Research Grants, on Advanced Medical Technology from Ministry of Health, Labour and Welfare, Japan.

\section{REFERENCES}

1) Patil S. D., Burgess D. J., "AAPS Newsmagazine," Vol. 6, No. 27, 2003.

2) Romano G., Micheli P., Pacilio C., Giordano A., Stem Cells, 18, 19 39 (2000).

3) Zhdanov R. I., Podobed O. V., Vlassov V. V., Bioelectrochemistry, 58, 53-64 (2002).

4) Brown M. D., Schatzlein A. G., Uchegbu I. F., Int. J. Pharm., 229, 121 (2001).

5) Felgner P. L., Gadek T. R., Holm M., Roman R., Chan H. W., Wenz M., Northrop J. P., Ringold G. M., Danielsen M., Proc. Natl. Acad. Sci. U.S.A., 84, 7413-7417 (1987).

6) Nabel G. J., Nabel E. G., Yang Z. Y., Fox B. A., Plautz G. E., Gao X., Huang L., Shu S., Gordon D., Chang A. E., Proc. Natl. Acad. Sci. U.S.A., 90, 11307-11311 (1993).

7) Hui K. M., Ang P. T., Huang L., Tay S. K., Gene Ther, 8, 783-790 (1997).

8) Caplen N. J., Alton E. W., Middleton P. G., Dorin J. R., Stevenson B. J., Gao X., Durham S. R., Jeffery P. K., Hodson M. E., Coutelle C., Nat. Med., 1, 39-46 (1995).

9) McLachlan G., Ho L. P., Davidson-Smith H., Samways J., Davidson H., Stevenson B. J., Carothers A. D., Alton E. W., Middleton P. G., Smith S. N., Kallmeyer G., Michaelis U., Seeber S., Naujoks K., Greening A. P., Innes J. A., Dorin J. R., Porteous D. J., Gene Ther., 3, 1113-1123 (1996).

10) Gill D. R., Southern K. W., Mofford K. A., Seddon T., Huang L., Sorgi F., Thomson A., MacVinish L. J., Ratcliff R., Bilton D., Lane D. J., Littlewood J. M., Webb A. K., Middleton P. G., Colledge W. H., Cuthbert A. W., Evans M. J., Higgins C. F., Hyde S. C., Gene Ther, 4, 199209 (1997)

11) Filion M. C., Phillips N. C., Biochim. Biophys. Acta, 1329, 345-356
(1997).

12) Aramaki Y., Takano S., Tsuchiya S., FEBS Lett., 460, 472-476 (1999).

13) Omidi Y., Hollins A. J., Benboubetra M., Drayton R., Benter I. F., Akhtar S., J. Drug Target, 11, 311-323 (2003).

14) Lappalainen K., Urtti A., Soderling E., Jaaskelainen I., Syrjanen K., Syrjanen S., Biochim. Biophys. Acta, 1196, 201-208 (1994).

15) Friend D. S., Papahadjopoulos D., Debs R. J., Biochim. Biophys. Acta, 1278, 41-45 (1996).

16) Yew N. S., Wang K. X., Przybylska M., Bagley R. G., Stedman M., Marshall J., Scheule R. K., Cheng S. H., Hum. Gene Ther., 10, 223 234 (1999).

17) Dow S. W., Fradkin L. G., Liggitt D. H., Willson A. P., Heath T. D., Potter T. A., J. Immunol., 163, 1552-1561 (1999).

18) Bird A. P., Nature (London), 321, 209-213 (1986).

19) Afshari C. A., Nuwaysir E. F., Barrett J. C., Cancer Res., 59, 47594760 (1999).

20) Oda E, Ohki R., Murasawa H., Nemoto J., Shibue T., Yamashita T., Tokino T., Taniguchi T., Tanaka N., Science, 288, 1053-1058 (2000).

21) Yakovlev A. G., Di Giovanni S., Wang G., Liu W., Stoica B., Faden A. I., J. Biol. Chem., 279, 28367-28374 (2004).

22) Li J., Lee B., Lee A. S., J. Biol. Chem., 281, 7260-7270 (2006).

23) McCullough K. D., Martindale J. L., Klotz L. O., Aw T. Y., Holbrook N. J., Mol. Cell Biol., 21, 1249-1259 (2001).

24) Oyadomari S., Mori M., Cell Death Differ., 11, 381-389 (2004).

25) Marciniak S. J., Yun C. Y., Oyadomari S., Novoa I., Zhang Y., Jungreis R., Nagata K., Harding H. P., Ron D., Genes Dev., 18, 3066-3077 (2004).

26) Zinszner H., Kuroda M., Wang X., Batchvarova N., Lightfoot R. T., Remotti H., Stevens J. L., Ron D., Genes Dev., 12, 982-995 (1998).

27) Karin M., Liu Z., Zandi E., Curr. Opin. Cell Biol., 9, 240-246 (1997).

28) Guyton K. Z., Xu Q., Holbrook N. J., Biochem. J., 314, 547-554 (1996).

29) Tang J. R., Nakamura M., Okura T., Takata Y., Watanabe S., Yang Z. H., Liu J., Kitami Y., Hiwada K., Biochem. Biophys. Res. Commun. 290, 1255-1259 (2002).

30) Qiao D., Im E., Qi W., Martinez J. D., Biochim. Biophys. Acta, $\mathbf{1 5 8 3}$ 108 -116 (2002).

31) Hai T., Hartman M. G., Gene, 273, 1-11 (2001).

32) Cai Y., Zhang C., Nawa T., Aso T., Tanaka M., Oshiro S., Ichijo H., Kitajima S., Blood, 96, 2140-2148 (2000).

33) Zhang C., Kawauchi J., Adachi M. T., Hashimoto Y., Oshiro S., Aso T., Kitajima S., Biochem. Biophys. Res. Commun., 289, 718-724 (2001).

34) Wolfgang C. D., Chen B. P. C., Martindale J. L., Holbrook N. J., Hai T., Mol. Cell. Biol., 17, 6700-6707 (1997).

35) Huang R. P., Darland T., Okamura D., Mercola D., Adamson E. D., Oncogene, 9, 1367-1377 (1994).

36) Huang R. P., Liu C., Fan Y., Mercola D., Adamson E. D., Cancer Res., 55, 5054-5062 (1995).

37) Muthukkumar S., Nair P., Sells S. F., Maddiwar N. G., Jacob R. J., Rangnekar V. M., Mol. Cell Biol., 15, 6262-6272 (1995).

38) Nair P., Muthukkumar S., Sells S. F., Han S. S., Sukhatme V. P., Rangnekar V. M., J. Biol. Chem., 272, 20131-20138 (1997).

39) Bottone F. G., Jr., Moon Y., Alston-Mills B., Eling T. E., J. Pharmacol. Exp. Ther., 315, 668-677 (2005).

40) Spets H., Georgii-Hemming P., Siljason J., Nilsson K., JernbergWiklund H., Blood, 92, 2914-2929 (1998).

41) Summersgill J. T., Sahney N. N., Gaydos C. A., Quinn T. C., Ramirez J. A., Infect. Immune, 63, 2801-2803 (1995).

42) Kito M., Akao Y., Ohishi N., Yagi K., Biochem. Biophys. Res. Commun., 257, 771-776 (1999).

43) Ishihara T., Aga M., Hino K., Ushio C., Taniguchi M., Iwaki K., Ikeda M., Kurimoto M., Biomed. Res., 26, 179-185 (2005). 